\title{
BMJ Open Paid and unpaid working hours among Swedish men and women in relation to depressive symptom trajectories: results from four waves of the Swedish Longitudinal Occupational Survey of Health
}

\author{
Paraskevi Peristera, ${ }^{1}$ Hugo Westerlund, ${ }^{1,2}$ Linda L Magnusson Hanson ${ }^{1}$
}

To cite: Peristera $\mathrm{P}$, Westerlund $\mathrm{H}$, Magnusson Hanson LL. Paid and unpaid working hours among Swedish men and women in relation to depressive symptom trajectories: results from four waves of the Swedish Longitudinal Occupational Survey of Health. BMJ Open 2018;8:e017525. doi:10.1136/ bmjopen-2017-017525

- Prepublication history and additional material for this paper are available online. To view these files, please visit the journal online (http://dx.doi. org/10.1136/bmjopen-2017017525).

Received 28 April 2017 Revised 23 February 2018 Accepted 25 April 2018
Check for updates

${ }^{1}$ Stress Research Institute, Stockholm University, Stockholm, Sweden

${ }^{2}$ Department of Clinical Neuroscience, Karolinska Institutet, Stockholm, Sweden

Correspondence to Dr Paraskevi Peristera; paraskevi.peristera@su.se

\section{ABSTRACT}

Background Long working hours and unpaid work are possible risk factors for depressive symptoms. However, little is known about how working hours influence the course of depressive symptoms. This study examined the influence of paid, unpaid working hours and total working hours on depressive symptoms trajectories.

Methods The study was based on data from four waves of the Swedish Longitudinal Occupational Survey of Health (SLOSH 2008-2014). We applied group-based trajectory modelling in order to identify trajectories of depressive symptoms and studied paid and unpaid working hours and total working hours as risk factors.

Results Six trajectory groups were identified with symptoms: 'very low stable', 'low stable', 'doubtful increasing', 'high decreasing', 'mild decreasing' and 'high stable'. More time spent on unpaid work was associated with the 'low stable' (OR 1.16, 95\% Cl 1.04 to 1.30 ) and the 'high stable (OR 1.40, $95 \% \mathrm{Cl} 1.18$ to 1.65) symptom trajectories compared with being in the 'very low stable' symptom group. In addition, more total working hours was associated with a higher probability of having 'high decreasing' (OR 1.30, 95\% Cl 1.14 to 1.48) and 'high stable' (OR $1.22,95 \% \mathrm{Cl} 1.01$ to 1.47 ) symptoms, when adjusting for sex, age, civil status and socioeconomic status. The results, however, differed somewhat for men and women. More unpaid working hours was more clearly associated with higher symptom trajectories among women. More total working hours was associated with 'high stable' symptoms among women only.

Conclusions This study supported heterogeneous individual patterns of depressive symptoms over time among the Swedish working population. The results also indicate that a higher burden of unpaid work and longer total working hours, which indicate a double burden from paid and unpaid work, may be associated with higher depressive symptom trajectories, especially among women.
Strengths and limitations of this study

- This study was conducted in a sample from the general working population and with measures of depressive symptom every second year over a period of 8 years.

- In contrast to studies of depression trajectories in clinical population, studies in the entire population may more accurately represent the true underlying continuum of the disorder.

- Group-based trajectory modelling provides a flexible way to summarise data in an easy and understandable way and identify heterogeneity in the sample.

- A longer time series of measurement may have contributed to more power for identifying heterogeneity in symptoms over time.

- The sample is probably characterised by relatively healthy individuals with high educational level and so on, leading to potential underestimation of relationships between working hours and depressive symptoms.

\section{INTRODUCTION}

Mental health problems and especially depression are of major public health concern owing to the high prevalence and substantial negative consequences on personal functioning but also work productivity. ${ }^{1}$ It is well known that onset of depression may vary between individuals and that symptoms occasionally recur over the life course.

Some long-term patterns of depressive symptoms may also be associated with more functional limitations, ${ }^{2}$ and it has been suggested that different risk factors may be associated with different long-term patterns. ${ }^{34}$ It has previously been indicated that factors such as problems with peers and parents, alcohol/tobacco/drug use, parental history 
of depression and negative cognitive styles could lead to worse depression trajectories over time among children/ adolescents. Among older people, poor self-rated health, history of somatic illness, functional and cognitive impairment and low social support have been associated with negative course of symptoms. Stressful life events has also a found to be a predictor of poor depressive symptom trajectories. ${ }^{5}{ }^{6}$ However, little is known about the influence of work-related characteristics on different longterm patterns of depressive symptoms.

Work stressors such as high work demands or high demands in combination with low control (job strain) have generally been implied as risk factors for depressive symptoms. ${ }^{7-9}$ Long working hours has also been associated with several serious health outcomes such as stroke and coronary heart disease, ${ }^{10}$ and diabetes among people with low socioeconomic status, ${ }^{211}$ as well as depressive states. ${ }^{4-9}{ }^{12-14}$ It has been suggested that work stress may be one of the reasons for negative health effects of long working hours. Long working hours may also be associated with limited time for recuperation and lead to poorer health behaviours. ${ }^{15}$ In the modern working life, there is an increased risk that working times are extended beyond the contracted hours, which could have serious implications for recovery and health. However, the potential health effects associated with long working hours may also depend on non-work responsibilities.

In general, women still spend far more time than men on unpaid work ${ }^{16}$ and they can be at risk of 'a double burden' of both paid and unpaid work. A double burden or 'high total workload' in terms of hours spent on paid/ unpaid work has been suggested to be associated with work stress and to contribute to common physical and mental symptoms, ${ }^{17-19}$ but more knowledge is needed on both changes in stress from workload in paid and unpaid work, and the interplay between these stressors, over the life course and how they influence health among men and women. ${ }^{20}$

A better understanding of the health risks associated with long working hours and total workload can allow for better scheduling, legislation and prioritisation of preventive measures.

The aim of this study was to examine how time spent on paid and unpaid work as well as total working hours are associated with different depressive symptoms trajectories among Swedish men and women.

\section{METHODS}

\section{Study population}

The study population consisted of participants from Swedish Longitudinal Occupational Survey of Health (SLOSH) study, a nationally representative longitudinal cohort study with repeat self-reported measures every second year. ${ }^{21}$ SLOSH started in 2006 as a follow-up of participants in the Swedish Work Environment Survey (SWES) 2003 ( $\mathrm{n}=9214)$. SWES 2003 participants were asked to complete questionnaires again in 2008, 2010,
2012, 2014 and 2016. Respondents from SWES 2005 were also added to the cohort in the next SLOSH wave in 2008 (raising the number of cohort members to 18917) and asked to respond to follow-up questionnaires every second year. Postal self-completion follow-up questionnaire were sent out to all eligible SWES participants each wave, one for those that currently work at least $30 \%$ or full time and one for people working less or those who had left the labour force temporarily or permanently. Four waves have been used in the present study: 2008, 2010, 2012 and 2014. The total number of invited participants were $18639,20298,17434$, and 38659 , respectively, with overall response rates between $62 \%$ and $57 \%$.

To allow for analyses of trajectories of depressive symptoms and temporal changes in working times, the present study is based on those SWES 2003 and 2005 participants who responded in all four waves (2008-2014) with a total of 6300 individuals (figure 1). Women, older, highly educated and married people are generally over-represented among the respondents to SLOSH. A comparison of demographic characteristics between all respondents (2008) $(\mathrm{n}=11441)$ and the study sample further showed that the study sample consisted of a higher proportion of women, university educated and with higher mean age and children at home than those excluded from the sample because of non-response (2010-2014). Depressive symptoms scores were, however, generally a bit lower among the study subjects, as was the proportion of long working hours and long hours of unpaid work. Informed consent was obtained from all respondents. More information about the cohort can be found elsewhere. ${ }^{22}$

\section{Measures}

Depressive symptoms were measured with a brief subscale from the Symptom Checklist (SCL-90), labelled symptom checklist core depression scale $\left(\mathrm{SCL}-\mathrm{CD}_{6}\right),{ }^{23}$ which assesses perception of being troubled by: feeling blue, feeling no interest in things, feeling lethargy or low in energy, worrying too much about things, blaming yourself for things and feeling everything is an effort, quantified on a five-category scale from $0=$ not at all to $4=$ extremely. The six items represent core symptoms, selected based on principals of clinical validity. The scale was validated and was found to have good psychometric properties making it suitable to add into a composite score indicative of depression severity. ${ }^{23}$

Time use was also measured repeatedly in 2008-2014 by a modified version of a measure, developed and psychometrically evaluated by Mårdberg et al. ${ }^{24}$ In addition to hours/week in paid employment and overtime at work, constituting a measure of paid working hours, the instrument covers unpaid work activities, such as household duties (mending, sewing, laundry and gardening), childcare (homework/teaching, care-taking and playing) and other unpaid duties (voluntary work in unions and organisations, care of sick or elderly relatives). Hours/week spent on household duties (shopping, cleaning, cooking, mending, sewing, laundry and gardening), on childcare 
SWES 2003 participants

SWES 2005 participants

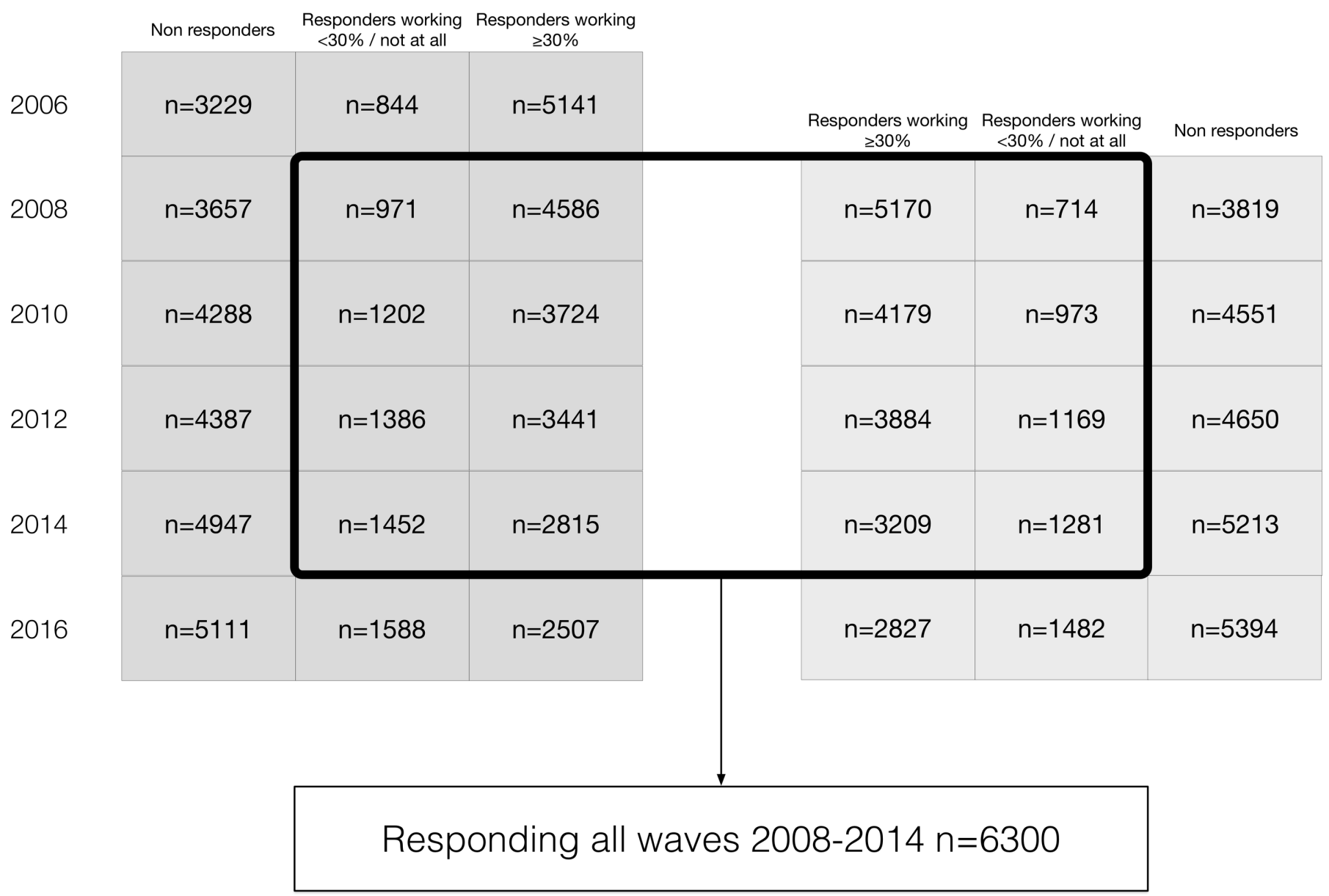

SWES: The Swedish Work Environment Survey

Figure 1 Total number of respondents/non-respondents to the Swedish Longitudinal Occupational Survey of Health (SLOSH) among the SLOSH sample originally participating in the Swedish Work Environment Surveys (SWES) 2003 and 2005, as well as number of individuals included in the analytic sample.

(homework/teaching, care-taking and playing), on informal care, and other duties were added to a measure of unpaid working hours. The respondents were asked to indicate number of hours according to prespecified categories in 2010-2014, which were used to divide working hours into five categories that were similar for all waves and comparable with some of the previous literature on long working hours ${ }^{10}$ : $:<37,37-39,40-49,50-59$ and $60+$ working hours/week. Unpaid working hours was also divided into five categories: $<8,8-14,15-21,22-28$, $29+$ hours on average/week. The total number of hours spent on paid and unpaid work constituted the total working hours measure (reflecting 'total workload') and was divided into the following five categories: $<42,42-57$, $58-67,68-80$ and $>80$ hours/week. These categories were partly in line with previous literature. ${ }^{18}$

\section{Statistical analysis}

Group-based trajectory modelling (GBTM) was used in order to identify distinct groups of individual trajectories within the population and examine whether working hours predicts the course of depressive symptoms over time. This is a semiparametric model-based clustering technique that allows the identification of groups of individuals following a similar progression of an outcome over time in a flexible and easy way. ${ }^{26}$ The trajectory model was fitted using maximum likelihood methods allowing for incomplete data and assuming missing at random data. We used calendar time rather than age as the underlying time scale, since subcohort effects could not be ruled out with a cohort sequential design.

In order to select the best model, we followed Nagins' recommended two-step procedure. First, the number of latent trajectories was selected. Models with one to eight groups were estimated starting with a single trajectory model described by a cubic polynomial equation to capture the relationship between time (waves) and depressive symptoms, and continuing with models with increasing number of groups. Estimation of depression trajectories was accomplished using the censored normal model, which is appropriate for continuous data. 
The Bayesian Information Criterion (BIC) was mainly used in order to determine the number of subgroups. ${ }^{2627}$ The magnitude of difference in BIC, the Bayes factor as well as the BIC-based probability approximation were used to choose between more complex and simpler models. ${ }^{27-29}$ However, because BIC sometimes keeps improving when adding trajectory groups, ${ }^{26}$ we further considered the significance of polynomial terms (at the confidence level alpha 0.05), the values of group membership probabilities and of average posterior probability (entropy) with recommended value greater than $0.7^{26} 28-30$ and when the model no longer captured new distinctive features of the data as complementary criterions for selecting the best model. Because of a relatively large sample, we allowed for trajectory groups consisting of a minimum of $1 \%$ of the sample.

After selecting the optimal model in terms of number of groups, we selected the shape for each of these groups. Then conditional on the best model, time-stable covariates (risk factors) were inserted in the model by assuming that these risk factors influence the probability of membership to a particular trajectory group. Paid and unpaid working hours were considered simultaneously relative to the defined trajectory groups as time-invariant covariates (risk factors) in the main analyses to allow for a temporal precedence of working hours (labelled model 1). Also total working hours was modelled separately (labelled model 2). Coefficients for risk factors indicate the increase in log odds of being in a trajectory (relative to the lowest group) per unit change in the risk factor. ${ }^{26}$ Unadjusted models as well as models adjusted for sex (0 men, 1 women), age, civil status (0 not married, 1 married or cohabiting) and socioeconomic status ${ }^{31}$ were presented. We further conducted the same analyses for men and women separately since a significant interaction effect was found for sex and among participants working full time only. The latter was done to exclude those with part time from the reference group in the analyses of paid working hours, since those with part-time work may differ from full-time workers with respect to, for example, health and caring responsibilities. We also fitted models with working hours as categorical variables. Working hours were, however, alternatively considered as time-varying covariates to account for the time-varying nature. Since health effects of long working hours may be at least partly attributed to poor working conditions, we also tested if there was an interaction between long working hours and job strain (the combination between high job demands and low control). ${ }^{32-34}$

The GBTM analyses were conducted using the PROC TRAJ procedure developed by Jones and Nagin, which can be downloaded from http: //www.andrew.cmu.edu/ user/bjones ${ }^{29}{ }^{35}$ in the SAS software (V.9.4).

\section{Patient and public involvement}

The study was based on a sample of men and women from the general Swedish population, originally in paid work. The development of the research question, design of the study, recruitment and conduct of the study did not directly involve patients. The results of the study have also been presented at scientific conferences, will be disseminated to study participants through the SLOSH website (www.slosh.se) and/or the Stress Research Institute website (www.stressforskning.su.se) and may be presented at seminars and communications with labour market representatives.

\section{RESULTS}

Table 1 shows some descriptive characteristics of the study sample. Most of the study participants were in middle age or in mature adulthood at wave 2 (2008). A high proportion were married or cohabiting and about $40 \%$ had children living at home. Most were working full time with a day time work schedule. About $20 \%$ of the population had long paid working hours, that is, worked more than 50 hours per week, and a relatively high proportion had long unpaid working hours, that is, was spending 21 hours or more on unpaid work per week. Almost $10 \%$ had a long total working hours, that is, was spending over 80 hours per week on paid and/or unpaid work. Women generally worked longer in total (mean hours of total work: 65.02 hours) compared with men (mean hours of total work: 60.07 hours), while men generally spent more time on paid work (mean hours of paid work for men: 45.59 hours; mean hours of unpaid work: 14.3 hours) and women more time on unpaid work (mean hours of paid work: 45.09 and mean hours of unpaid work; 20.07 hours).

Evaluation of the different models resulted in the selection of a model with six trajectories with a linear order for four groups suggesting a linearly decreasing or increasing trajectory and a cubic order for two of the groups suggesting a trajectory where there are two turning points (inflections): a maximum and a minimum in depressive symptoms (BIC: -62598.42; entropy: 0.8). BIC continued to decrease for models with increasing number of groups (online supplementary table I). However, visual examination of models with four five, six and seven groups indicated that the six-group model identified distinctive features of the data (average posterior probabilities above $0.8)$. Figure 2 depicts the shapes of the six trajectories as well as their class sizes. The pattern of symptoms over time could be described as either 'very low stable', 'low stable', 'doubtful increasing', 'high decreasing', 'mild decreasing' and 'high stable'. The trajectories named 'very low stable', 'low stable' and 'stable high' followed a slight downward linear trend over time but remained either at a no depression level $(<7$ on the depression scale) or between moderate to severe level $(>11$ and $>15$, respectively, on the depression scale) ${ }^{25}$ The trajectory named 'mild decreasing' followed a slightly decreasing trend until year 2012 (wave 4) and slightly increasing afterwards. Symptoms varied from mild $(>9$ and $<11$ on the depression scale) to doubtful $(>6$ and $<10$ on the depression scale) depression. The trajectory named 'doubtful increasing' followed a slight increasing linear 
Table 1 Characteristics of the study sample in terms of demographic characteristics and workload from paid and unpaid work in 2008 (wave 2, SLOSH data)

\begin{tabular}{|c|c|c|c|}
\hline & All & Women & Men \\
\hline \multicolumn{4}{|l|}{ Age (\%) } \\
\hline Early adulthood (19-34) & 8.9 & 10.2 & 7.06 \\
\hline Middle life (35-49) & 30.6 & 32.1 & 28.69 \\
\hline Mature adulthood (50-70) & 60.5 & 51.3 & 64.25 \\
\hline Sex (\% females) & 58.0 & & \\
\hline $\begin{array}{l}\text { Civil status ( } \% \text { married or } \\
\text { cohabiting) }\end{array}$ & 79.7 & 78.4 & 81.56 \\
\hline Children at home (\%) & 40.9 & 41.9 & 39.6 \\
\hline \multicolumn{4}{|l|}{ SEI (\%) } \\
\hline Unskilled manual workers & 14.8 & 14.1 & 15.8 \\
\hline Skilled manual workers & 14.4 & 12.4 & 17.1 \\
\hline $\begin{array}{l}\text { Assistant non-manual } \\
\text { employees }\end{array}$ & 12.6 & 16.5 & 7.1 \\
\hline $\begin{array}{l}\text { Intermediate non-manual } \\
\text { employees }\end{array}$ & 31.5 & 34.0 & 27.9 \\
\hline Higher non-manual employees & 20.5 & 19.1 & 22.8 \\
\hline Self-employed & 6.2 & 3.8 & 9.5 \\
\hline Full-time work (\%) & 77.4 & 67.6 & 90.7 \\
\hline \multicolumn{4}{|l|}{ Work schedule (\%) } \\
\hline Day time & 78.0 & 76.5 & 80.1 \\
\hline Night work & 6.2 & 3.1 & 1.9 \\
\hline Shift work excl. nights & 15.8 & 4.32 & 3.13 \\
\hline \multicolumn{4}{|l|}{ Paid working hours per week (\%) } \\
\hline$<37$ & 25.2 & 32.2 & 16.1 \\
\hline $37-39$ & 5.3 & 6.4 & 3.9 \\
\hline $40-49$ & 50.4 & 46.8 & 55.3 \\
\hline $50-59$ & 12.1 & 9.7 & 15.2 \\
\hline $60+$ & 6.9 & 4.9 & 9.5 \\
\hline \multicolumn{4}{|l|}{ Unpaid working hours per week (\%) } \\
\hline$<8$ & 19.1 & 10.7 & 30.2 \\
\hline $8-14$ & 26.9 & 24.5 & 30.1 \\
\hline $15-21$ & 22.4 & 26.6 & 17.1 \\
\hline $22-28$ & 13.4 & 16.3 & 9.6 \\
\hline $29+$ & 18.1 & 21.9 & 13.1 \\
\hline \multicolumn{4}{|l|}{ Total working hours per week (\%) } \\
\hline$<42$ & 12.6 & 12.8 & 12.1 \\
\hline $42-57$ & 34.2 & 31.3 & 37.9 \\
\hline $58-67$ & 24.9 & 24.4 & 22.9 \\
\hline $68-80$ & 18.6 & 19.3 & 17.6 \\
\hline$>80$ & 9.7 & 9.9 & 9.5 \\
\hline
\end{tabular}

SEl, Swedish socio-economic classification; SLOSH, Swedish Longitudinal Occupational Survey of Health.

trend but remained either at doubtful or mild depression level. Finally the trajectory named 'high decreasing' followed a steep downward trend until year 2010 (wave 3) and a slightly decreasing trend thereafter. The symptoms varied from severe depression to no depression levels.

The majority of individuals were classified in either the 'very low stable' $(49.1 \%)$ or 'low stable' $(23.4 \%)$ group. The 'high decreasing' group represented the smallest group $(1.3 \%)$ and the 'doubtful increasing' represented $8.4 \%$ of the sample. Both the 'high decreasing' group and the 'doubtful increasing' group followed a quadratic trend with two turning points. Altogether, there were four favourable ('mild decreasing', 'high decreasing', 'low stable' and 'very low stable') and two unfavourable ('doubtful increasing' and 'high stable') trajectories.

A description of the demographic characteristics and the distribution of working hours in the year 2008 for the six trajectory groups are given in table 2 . The mean age was, for example, lowest in the 'high stable' trajectory (47.0 years), followed by the 'doubtful increasing' group (47.6 years). Overall, there was a higher proportion of women in the unfavourable trajectories. Especially unpaid working hours and total working hours varied between the groups. A higher proportion of individuals with unpaid working hours and long of total working hours were observed in the 'doubtful increasing' and the 'high stable' group.

Table 3 reports the results of the multinomial logistic regression models in $\log$ ORs (estimate), SEs and ORs, with the 'very low stable' group as reference group. Model 1 presents the results from a model including both paid and unpaid working hours, while model 2 presents the results of a model analysing the influence of total working hours separately. The results showed that unpaid working hours at the baseline measurement (2008) was associated with a significantly higher likelihood of being in all the trajectory groups as compared with being in the reference group, but no significant associations were found for paid working hours. Longer total working hours was associated with increased likelihood of being in the 'low stable', 'doubtful increasing', 'mild decreasing' and 'high stable' group. Sex, age and civil status and socioeconomic status were included in the adjusted models as additional risk factors for the trajectory group membership. Estimates from the adjusted model with respect to paid/unpaid working hours were relatively similar to those in the unadjusted model. However, longer unpaid working hours were now associated with a significantly higher likelihood of being in 'low stable' and 'high stable' as compared with the reference group. With respect to longer total working hours, there was an increased likelihood of being in the 'high decreasing' (OR: $1.30 ; 95 \%$ CI1.14 to 1.48 ) and 'high stable' group (OR: 1.22; 95\% CI 1.01 to 1.47). In supplementary analyses of longer paid working hours separately, no significant associations between paid working hours and the trajectory groups were observed. Results were also similar in a subsample of fulltime employees only. No clear associations was, however, observed in analyses with working hours as categorical variables but which may be due to lack of power. Moreover, the risk estimates for paid working hours were not significantly different among people with or without job strain (data not shown). 

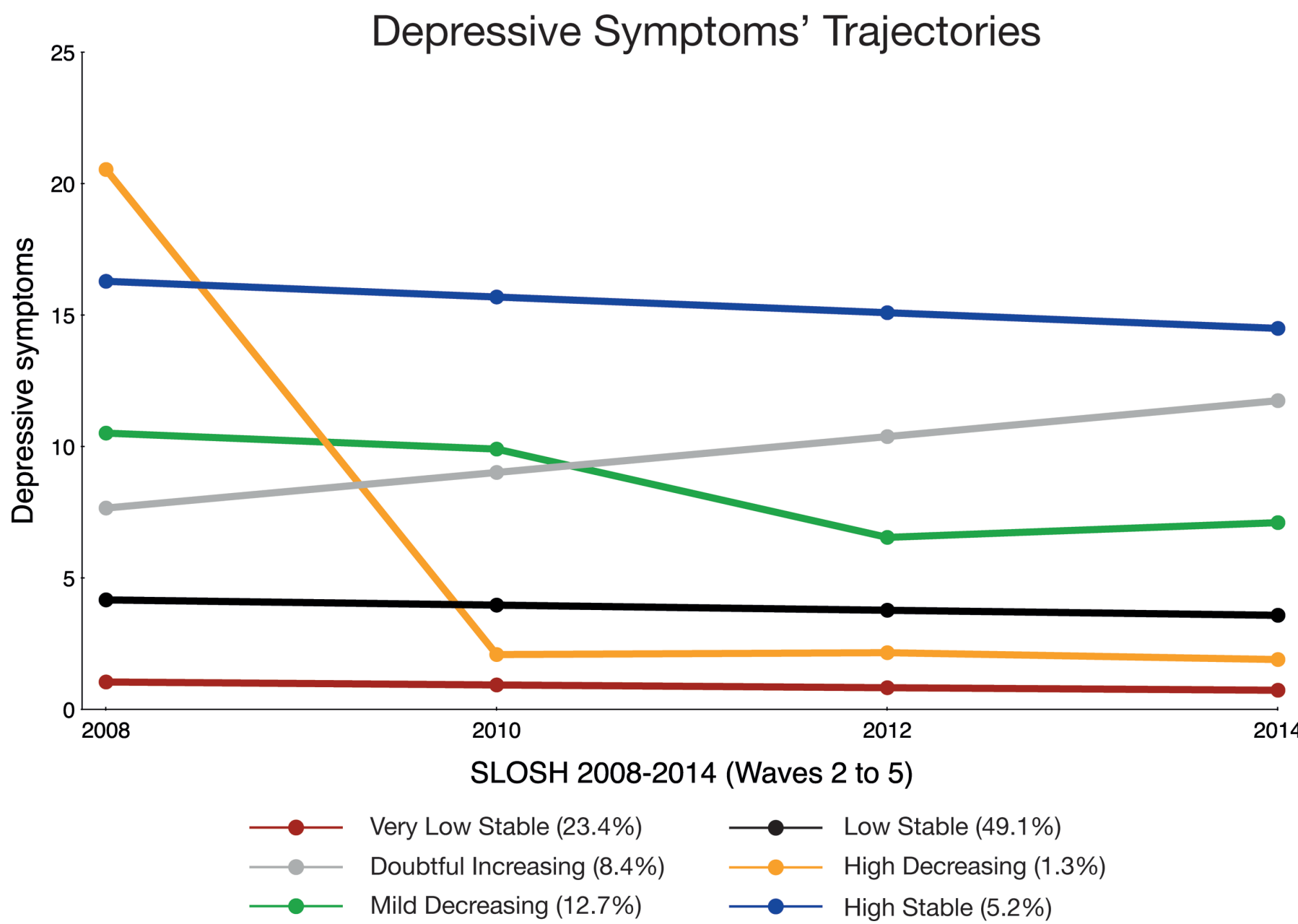

Figure 2 Trajectories of depressive symptoms from 2008 to 2014 (waves 2-5 in SLOSH data); six groups of depressive symptoms were identified: very low stable (group 1: $23.4 \%$ of the sample), low stable (group 2: $49.1 \%$ of the sample), doubtful increasing (group 3: $8.4 \%$ of the sample), high decreasing (group 4: 1.3\% of the sample), mild decreasing (group 5: 12.7\% of the sample), high stable (group 6: $5.2 \%$ of the sample). SLOSH, Swedish Longitudinal Occupational Survey of Health.

An interaction between total working hours and sex was on the hand noted. The analyses were therefore also stratified by sex. The separate trajectory groups identified for men and women are shown in online supplementary figure I and supplementary figure II. Among men, the best solution resulted in only five trajectory groups, whereas six groups were identified among women. The trajectories were relatively similar to the ones illustrated in figure 2. In the adjusted models, men with more unpaid working hours were more likely to be in 'doubtful stable' or 'high stable' groups, while no significant associations were found for paid working hours (online supplementary table II). Unpaid working hours were also associated with an increased likelihood of higher symptom trajectories compared with the reference group for women, while no significant associations were found for paid working hours (online supplementary table III). For total working hours among men, we found an increased likelihood of being in the 'doubtful stable' group, while longer total working hours for women was associated with increased likelihood in the 'high decreasing' and 'high stable' groups compared with the very low stable group (adjusted models; online supplementary table II and online supplementary table III). Hence, the association between total workload and high stable depressive symptoms was only apparent among women.

In analyses with working hours as time-varying covariate, adjusting for sex, age, civil status and socioeconomic status, longer paid working hours increased the depressive symptom trajectory in the 'low stable', 'doubtful increasing' and high stable' group. Longer unpaid working hours also raised the trajectory in the 'doubtful increasing' group but decreased the depressive symptoms in the 'mild decreasing' group. Longer total working hours, however, significantly increased depressive symptoms in both the 'very low stable', 'low stable', 'doubtful increasing' and 'high stable' group but not in the 'high or mild decreasing' groups (online supplementary table IV).

\section{DISCUSSION}

The current study identified six distinct depressive symptoms trajectories. Previous population-based studies 
Table 2 Characteristics of the trajectory groups in terms of demographic characteristics and workload from paid and unpaid working hours in 2008 (wave 2, SLOSH data)

\begin{tabular}{|c|c|c|c|c|c|c|}
\hline & $\begin{array}{l}\text { Very low } \\
\text { stable } \\
(n=1447)\end{array}$ & $\begin{array}{l}\text { Low stable } \\
(\mathrm{n}=3213)\end{array}$ & $\begin{array}{l}\text { Doubtful } \\
\text { increasing } \\
(n=474)\end{array}$ & $\begin{array}{l}\text { High } \\
\text { decreasing } \\
(n=74)\end{array}$ & $\begin{array}{l}\text { Mild } \\
\text { decreasing } \\
(\mathrm{n}=755)\end{array}$ & $\begin{array}{l}\text { High stable } \\
(\mathrm{n}=328)\end{array}$ \\
\hline Mean age (years) & 55.2 & 51.1 & 47.6 & 54.1 & 49.6 & 46.8 \\
\hline Sex (\% females) & 48.2 & 58.0 & 68.1 & 69.4 & 65.0 & 71.3 \\
\hline Civil status ( $\%$ married) & 82.5 & 80.6 & 76.3 & 71.6 & 77.2 & 71.8 \\
\hline \multicolumn{7}{|l|}{ Socioeconomic in status (\%) } \\
\hline Unskilled manual workers & 15.3 & 13.9 & 16.0 & 13. 9 & 16.0 & 17.0 \\
\hline Skilled manual workers & 16.4 & 13.8 & 14.0 & 6.9 & 14.6 & 12.6 \\
\hline Assistant non-manual employees & 12.8 & 12.0 & 12.3 & 15.3 & 13.5 & 15.1 \\
\hline Intermediate non-manual employees & 17.9 & 32.3 & 32.9 & 27.8 & 31.8 & 28.7 \\
\hline Higher non-manual employees & 8.0 & 22.3 & 18.6 & 22.2 & 19.2 & 20.8 \\
\hline Self-employed & 8.2 & 5.7 & 6.1 & 13.9 & 4.6 & 5.9 \\
\hline \multicolumn{7}{|l|}{ Paid working hours per week (\%) } \\
\hline$<37$ & 25.3 & 23.8 & 27.7 & 30.0 & 27.9 & 27.8 \\
\hline $37-39$ & 5.8 & 5.4 & 6.3 & 8.3 & 4.4 & 2.9 \\
\hline $40-49$ & 49.7 & 51.4 & 50.3 & 35.0 & 47.9 & 53.5 \\
\hline $50-59$ & 11.3 & 12.8 & 10.8 & 18.3 & 11.3 & 10.6 \\
\hline $60 / 61+$ & 7.8 & 6.6 & 5.2 & 8.3 & 8.4 & 5.1 \\
\hline \multicolumn{7}{|l|}{ Unpaid working hours per week (\%) } \\
\hline$<8$ & 25.5 & 19.3 & 11.8 & 15.4 & 15.4 & 11.0 \\
\hline $8-14$ & 28.9 & 27.9 & 20.3 & 26.9 & 25.4 & 22.4 \\
\hline $15-21$ & 21,7 & 22.6 & 23.4 & 26.9 & 22.5 & 21.2 \\
\hline $22-28$ & 12.6 & 12.8 & 14.9 & 17.3 & 14.2 & 17.1 \\
\hline $29+$ & 11.3 & 17.3 & 29.6 & 13.5 & 22.5 & 28.2 \\
\hline \multicolumn{7}{|l|}{ Total working hours per week (\%) } \\
\hline$<42$ & 15.9 & 11.8 & 11.0 & 10 & 12.3 & 9.5 \\
\hline $42-57$ & 38.4 & 35.1 & 25.9 & 44.0 & 30.3 & 27.8 \\
\hline $58-67$ & 21.5 & 25.8 & 28.2 & 18.0 & 24.6 & 26.9 \\
\hline $68-80$ & 16.6 & 18.4 & 20.6 & 18.0 & 20.4 & 21.2 \\
\hline$>80$ & 7.7 & 8.8 & 14.2 & 10.0 & 12.3 & 14.5 \\
\hline
\end{tabular}

SLOSH, Swedish Longitudinal Occupational Survey of Health.

have also shown that stable patterns are common such as stable low symptoms, ${ }^{5}$ which is in line our findings. A small group with stable high symptoms, as in the present study, have also commonly been found in other studies. ${ }^{25}$ Patterns with varying degree of symptoms over time are more seldom observed. ${ }^{5}$ However, it has also been found that a considerable proportion of the general population experience a stable recovery after a depressive episode. ${ }^{2}$ The patterns observed in this study are thus generally in line previous findings and expectations.

This work further suggested that total working hours and unpaid working hours is associated with different long-term trajectories of depressive symptoms, but no association was noted for paid working hours. The present study thus conflict with an association between long working hours and depression as found in previous work. ${ }^{12}$ However, there are indications that only more extreme weekly working hours are associated with poorer health, ${ }^{10} 25$ which may partly explain why we did not observe any association between time spent on paid work and depressive symptom trajectories in the present study. Also the inclusion of part time work in this study may have played a role, although sensitivity analyses among full-time employees showed similar results. The study, however, indicate that a longer total working hours or unpaid working hours is associated with certain patterns of depressive symptoms over time. This is the first study to our knowledge on the relationship between unpaid working and total working hours and depressive symptom trajectories. The results indicated an association between unpaid working hours and total working hours and both favourable ('low stable' and 'high decreasing') 
Table 3 Results from the multinomial logistic regressions models estimating the probabilities of group membership according to $(A)$ paid working hours and unpaid working hours and (B) total working hours

\begin{tabular}{|c|c|c|c|c|c|}
\hline $\begin{array}{l}\text { Trajectory } \\
\text { groups }\end{array}$ & $\begin{array}{l}\text { Low } \\
\text { stable }\end{array}$ & $\begin{array}{l}\text { Doubtful } \\
\text { increasing }\end{array}$ & $\begin{array}{l}\text { High } \\
\text { decreasing }\end{array}$ & $\begin{array}{l}\text { Mild } \\
\text { decreasing }\end{array}$ & $\begin{array}{l}\text { High } \\
\text { stable }\end{array}$ \\
\hline & & Unadjusted & Models & & \\
\hline \multicolumn{6}{|l|}{ Model 1} \\
\hline & $\begin{array}{l}\text { Estimate OR } \\
\text { (SE) }(95 \% \mathrm{Cl})\end{array}$ & $\begin{array}{l}\text { Estimate OR } \\
\text { (SE) }(95 \% \mathrm{Cl})\end{array}$ & $\begin{array}{l}\text { Estimate OR } \\
\text { (SE) }(95 \% \mathrm{Cl})\end{array}$ & $\begin{array}{l}\text { Estimate OR } \\
\text { (SE) }(95 \% \mathrm{Cl})\end{array}$ & $\begin{array}{l}\text { Estimate OR } \\
\text { (SE) }(95 \% \mathrm{Cl})\end{array}$ \\
\hline $\begin{array}{l}\text { Paid working } \\
\text { hours }\end{array}$ & $\begin{array}{l}-0.010 .99 \\
(0.01)(0.98 \text { to } 1.01)\end{array}$ & $\begin{array}{l}0.001 .00(0.00) \\
(0.99 \text { to } 1.01)\end{array}$ & $\begin{array}{l}-0.001 .00 \\
(0.01)(0.97 \text { to } 1.02)\end{array}$ & $\begin{array}{l}-0.010 .99 \\
(0.01)(0.98 \text { to } 1.00)\end{array}$ & $\begin{array}{l}-0.010 .99 \\
(0.01)(0.97 \text { to } 1.01)\end{array}$ \\
\hline $\begin{array}{l}\text { Unpaid working } \\
\text { hours }\end{array}$ & $\begin{array}{l}0.26^{*} 1.29 \\
(0.05)(1.17 \text { to } 1.43)\end{array}$ & $\begin{array}{l}0.28^{\star} 1.32 \\
(0.05)(1.20 \text { to } 1.45)\end{array}$ & $\begin{array}{l}0.25^{\star} 1.28 \\
(0.11)(1.03 \text { to } 1.60)\end{array}$ & $\begin{array}{l}0.54^{*} 1.72 \\
(0.06)(1.53 \text { to } 1.92)\end{array}$ & $\begin{array}{l}0.53^{*} 1.31 \\
(0.09)(1.11 \text { to } 1.54)\end{array}$ \\
\hline \multicolumn{6}{|l|}{ Model 2} \\
\hline & $\begin{array}{l}\text { Estimate OR } \\
\text { (SE) }(95 \% \mathrm{Cl})\end{array}$ & $\begin{array}{l}\text { Estimate OR } \\
\text { (SE) }(95 \% \mathrm{Cl})\end{array}$ & $\begin{array}{l}\text { Estimate OR } \\
\text { (SE) }(95 \% \mathrm{Cl})\end{array}$ & $\begin{array}{l}\text { Estimate OR } \\
\text { (SE) }(95 \% \mathrm{Cl})\end{array}$ & $\begin{array}{l}\text { Estimate OR } \\
\text { (SE) }(95 \% \mathrm{Cl})\end{array}$ \\
\hline \multirow[t]{2}{*}{$\begin{array}{l}\text { Total working } \\
\text { hours }\end{array}$} & $\begin{array}{l}0.17^{*} 1.18 \\
(0.06)(0.98 \text { to } 1.03)\end{array}$ & $\begin{array}{l}0.22^{*} 1.25 \\
(0.05)(1.12 \text { to } 1.39)\end{array}$ & $\begin{array}{l}0.131 .15 \\
(0.13)(0.88 \text { to } 1.49)\end{array}$ & $\begin{array}{l}0.39^{*} 1.47 \\
(0.06)(1.30 \text { to } 1.67)\end{array}$ & $\begin{array}{l}0.34^{*} 1.40 \\
(0.09)(1.16 \text { to } 1.68)\end{array}$ \\
\hline & & Adjusted & Models & & \\
\hline \multicolumn{6}{|l|}{ Model 1} \\
\hline & $\begin{array}{l}\text { Estimate OR } \\
\text { (SE) }(95 \% \mathrm{Cl})\end{array}$ & $\begin{array}{l}\text { Estimate OR } \\
\text { (SE) }(95 \% \mathrm{Cl})\end{array}$ & $\begin{array}{l}\text { Estimate OR } \\
\text { (SE) }(95 \% \mathrm{Cl})\end{array}$ & $\begin{array}{l}\text { Estimate OR } \\
\text { (SE) }(95 \% \mathrm{Cl})\end{array}$ & $\begin{array}{l}\text { Estimate OR } \\
\text { (SE) }(95 \% \mathrm{Cl})\end{array}$ \\
\hline $\begin{array}{l}\text { Paid working } \\
\text { hours }\end{array}$ & $\begin{array}{l}-0.010 .99 \\
(0.01)(0.98 \text { to } 1.00)\end{array}$ & $\begin{array}{l}0.001 .00 \\
(0.01)(0.99 \text { to } 1.01)\end{array}$ & $\begin{array}{l}0.371 .01 \\
(0.06)(0.89 \text { to } 1.14)\end{array}$ & $\begin{array}{l}0.131 .14 \\
(0.12)(0.90 \text { to } 1.45)\end{array}$ & $\begin{array}{l}0.33^{*} 1.40 \\
(0.09)(1.18 \text { to } 1.65)\end{array}$ \\
\hline $\begin{array}{l}\text { Unpaid working } \\
\text { hours }\end{array}$ & $\begin{array}{l}0.15^{\star} 1.16 \\
(0.06)(1.04 \text { to } 130)\end{array}$ & $\begin{array}{l}0.091 .10 \\
(0.05)(0.99 \text { to } 1.23)\end{array}$ & $\begin{array}{l}0.49^{*} 1.64 \\
(0.10)(1.34 \text { to } 2.02)\end{array}$ & $\begin{array}{l}0.29 * 1.35 \\
(0.12)(1.05 \text { to } 1.71)\end{array}$ & $\begin{array}{l}0.47^{*} 1.60 \\
(0.11)(1.29 \text { to } 1.982)\end{array}$ \\
\hline \multicolumn{6}{|l|}{ Model 2} \\
\hline & $\begin{array}{l}\text { Estimate OR } \\
\text { (SE) }(95 \% \mathrm{Cl})\end{array}$ & $\begin{array}{l}\text { Estimate OR(SE) } \\
(95 \% \mathrm{Cl})\end{array}$ & $\begin{array}{l}\text { Estimate OR } \\
\text { (SE) }(95 \% \mathrm{Cl})\end{array}$ & $\begin{array}{l}\text { Estimate OR } \\
\text { (SE) }(95 \% \mathrm{Cl})\end{array}$ & $\begin{array}{l}\text { Estimate OR } \\
\text { (SE) }(95 \% \mathrm{Cl})\end{array}$ \\
\hline $\begin{array}{l}\text { Total working } \\
\text { hours }\end{array}$ & $\begin{array}{l}0.061 .06 \\
(0.06)(0.94 \text { to } 1.19)\end{array}$ & $\begin{array}{l}0.081 .08 \\
(0.06)(0.96 \text { to } 1.21)\end{array}$ & $\begin{array}{l}0.26^{*} 1.30 \\
(0.07)(1.14 \text { to } 1.48)\end{array}$ & $\begin{array}{l}-0.030 .97(0.14) \\
(0.74 \text { to } 126)\end{array}$ & $\begin{array}{l}0.19^{*} 1.22 \\
(0.09)(1.01 \text { to } 1.47)\end{array}$ \\
\hline
\end{tabular}

Reference group: very low stable (group 1).

Estimates: log ORs and SEs (in parentheses).

$95 \% \mathrm{Cls}$ (in brackets).

and unfavourable ('high stable') trajectories. A higher risk of belonging to some of these groups such as the 'low stable' and 'high decreasing' groups may be explained by a higher initial level of depressive symptoms than those in the 'very low stable' group.

Complementary analyses showed that the depressive symptoms increased further in some groups, especially in the unfavourable groups with doubtful increasing and stable high symptoms, with an increase in total working hours over the period. This suggests that long working hours potentially due to a double burden of paid and unpaid work constitute a risk and should be considered in policy and prevention. Increased gender equality in terms of work conditions and unpaid work share may also contribute to lessen the burden in the society at large. More research is however needed to confirm our findings. Although we did observe that there was a stronger association between unpaid working hours and total working hours and high decreasing as well as stable high depressive symptoms among women than men, there were generally small differences men and women. This is in contrast to some earlier studies that have suggested that long working hours may be more detrimental to women's health, ${ }^{36-41}$ although the evidence is still scarce and inconclusive. ${ }^{42-44}$ Another study, however, observed similar associations between long working hours and health among men and women from Nordic countries characterised by the so-called dual breadwinner external care model (meaning participation of both parents on the labour market and outsourcing of care), while different associations were observed in other countries dominated by, for example, the male breadwinner model. ${ }^{45}$

Some strengths of the study are that it was conducted in a sample from the general working population and with measures of depressive symptom every second year over a period of 8 years. In contrast to studies of depression trajectories in clinical population, studies in the entire population may more accurately represent the true underlying continuum of the disorder. ${ }^{5}$ GBTM provides a flexible way to summarise data in an easy and understandable way and also introduce risk factors that may influence membership in trajectory groups and 
therefore identify heterogeneity in the sample. ${ }^{27}{ }^{46}$ We based the trajectories on four time points, which is above the minimum required for estimating quadratic trajectories. ${ }^{30}$ A longer time series of measurement may, however, have contributed to more power for identifying heterogeneity in symptoms over time, study onset versus recovery and so on and potential determinants of different trajectories. Dropout from the study may also have restricted the possibility to detect heterogeneity. Given that the subjects were originally working and repeatedly in paid work for more than $30 \%$ over the study period, the sample is probably characterised by relatively healthy individuals with high educational level and so on, leading to potential underestimation of relationships between working hours and depressive symptoms. Longitudinal sampling weights to make the analyses more representative of the source population was not available. Data were also missing on family history of mental health problems and childhood/adolescent characteristics, which may be predictors of depressive symptoms trajectories and workload and may confound the relationships of interest. In the main models, we chose to examine whether working hours at the start of the trajectory predicted the course of depressive symptoms in order to allow for temporal precedence of working hours, although working hours may also be changing or stable over the study period. This does not rule out that depressive symptoms at baseline may have biased reporting of working hours. However, later depressive symptoms are unlikely to influence the initial measurement of working hours. For power considerations, we also treated the data on working hours as continuous rather than categorical, which probably not optimal given that only more extreme hours may be associated with health consequences, but sensitivity analyses did not support associations between any of the specific categories and depressive symptoms trajectories. Finally, it would have been of interest to examine the impact of part-time work on depressive symptoms, but this was not possible due to power limitations.

All in all, the results indicate longer total working hours may increase the risk of higher depressive symptom trajectories. Since an unfavourable trajectory with stable or recurrent high depressive symptoms is associated with a poor prognosis, ${ }^{5}$ interventions with regard to working hours may contribute to limit the burden of depressive disorders in the population.

Acknowledgements The authors also wish to thank all participants, staff at Statistics Sweden and the Swedish National Board of Health and Welfare for making the study possible.

Contributors LLMH conceived the study. PP performed the analyses and drafted the manuscript. All authors contributed to the design and interpretation of data, critical revision of the work, gave final approval of the version to be published and agreed to be accountable for all aspects of the work.

Funding The authors are grateful for funding support from AFA Insurance, the Swedish Research Council for Health, Working life and Welfare and the Swedish Research Council.

Competing interests None declared.

Patient consent Not required.
Ethics approval The study has been approved by the Regional Research Ethics Board in Stockholm.

Provenance and peer review Not commissioned; externally peer reviewed.

Data sharing statement Swedish Longitudinal Occupational Survey of Health (SLOSH) data are not publicly available due to legal restrictions. Requests for data or results can be addressed to the SLOSH data manager data@slosh.se. More information can be found on the SLOSH website www.slosh.se.

Open Access This is an Open Access article distributed in accordance with the Creative Commons Attribution Non Commercial (CC BY-NC 4.0) license, which permits others to distribute, remix, adapt, build upon this work non-commercially, and license their derivative works on different terms, provided the original work is properly cited and the use is non-commercial. See: http://creativecommons.org/ licenses/by-nc/4.0/

(c) Article author(s) (or their employer(s) unless otherwise stated in the text of the article) 2018. All rights reserved. No commercial use is permitted unless otherwise expressly granted.

\section{REFERENCES}

1. Ferrari AJ, Charlson FJ, Norman RE, et al. Burden of depressive disorders by country, sex, age, and year: findings from the global burden of disease study 2010. PLoS Med 2013;10:e1001547.

2. Steinert C, Hofmann M, Kruse J, et al. The prospective long-term course of adult depression in general practice and the community. A systematic literature review. J Affect Disord 2014;152-154:65-75.

3. Colman I, Ataullahjan A. Life course perspectives on the epidemiology of depression. Can J Psychiatry 2010;55:622-32.

4. Papachristou E, Frangou S, Reichenberg A. Expanding conceptual frameworks: life course risk modelling for mental disorders. Psychiatry Res 2013;206:140-5.

5. Musliner KL, Munk-Olsen T, Eaton WW, et al. Heterogeneity in longterm trajectories of depressive symptoms: Patterns, predictors and outcomes. J Affect Disord 2016;192:199-211.

6. Hardeveld F, Spijker J, De Graaf R, et al. Prevalence and predictors of recurrence of major depressive disorder in the adult population. Acta Psychiatr Scand 2010;122:184-91.

7. Bonde JP. Psychosocial factors at work and risk of depression: a systematic review of the epidemiological evidence. Occup Environ Med 2008;65:438-45.

8. Netterstrøm B, Conrad N, Bech P, et al. The relation between workrelated psychosocial factors and the development of depression. Epidemiol Rev 2008;30:118-32.

9. Theorell T, Hammarström A, Aronsson G, et al. A systematic review including meta-analysis of work environment and depressive symptoms. BMC Public Health 2015;15:738.

10. Kivimäki M, Jokela M, Nyberg ST, et al. Long working hours and risk of coronary heart disease and stroke: a systematic review and metaanalysis of published and unpublished data for 603,838 individuals. Lancet 2015;386:1739-46.

11. Kivimäki M, Virtanen M, Kawachi I, et al. Long working hours, socioeconomic status, and the risk of incident type 2 diabetes: a meta-analysis of published and unpublished data from 222120 individuals. Lancet Diabetes Endocrinol 2015;3:27-34.

12. Bannai $A$, Tamakoshi $A$. The association between long working hours and health: a systematic review of epidemiological evidence. Scand $J$ Work Environ Health 2014;40:5-18.

13. Watanabe K, Imamura K, Kawakami N. Working hours and the onset of depressive disorder: a systematic review and meta-analysis. Occup Environ Med 2016;73:oemed-2016-103845-84.

14. Clark C, Pike C, McManus S, et al. The contribution of work and non-work stressors to common mental disorders in the 2007 Adult Psychiatric Morbidity Survey. Psychol Med 2012;42:829-42.

15. van der Hulst M. Long workhours and health. Scand J Work Environ Health 2003;29:171-88.

16. Moreno-Colom S. The gendered division of housework time: Analysis of time use by type and daily frequency of household tasks. Time \& Society 2017;26:3-27.

17. Krantz G, Ostergren PO. Double exposure. The combined impact of domestic responsibilities and job strain on common symptoms in employed Swedish women. Eur J Public Health 2001;11:413-9.

18. Berntsson L, Lundberg U, Krantz G. Gender differences in workhome interplay and symptom perception among Swedish whitecollar employees. J Epidemiol Community Health 2006;60:1070-6.

19. Krantz G, Berntsson L, Lundberg U. Total workload, work stress and perceived symptoms in Swedish male and female white-collar employees. Eur J Public Health 2005;15:209-14. 
20. Payne S, Doyal L. Older women, work and health. Occup Med 2010;60:172-7.

21. Magnusson Hanson LL, Theorell T, Oxenstierna G, et al. Demand, control and social climate as predictors of emotional exhaustion symptoms in working Swedish men and women. Scand J Public Health 2008;36:737-43.

22. Magnusson Hanson LL, Leineweber C, Persson V, et al. Cohort Profile: The Swedish Longitudinal Occupational Survey of Health (SLOSH). Int J Epidemiol 2018.

23. Magnusson Hanson LL, Westerlund H, Leineweber C, et al. The Symptom Checklist-core depression (SCL-CD6) scale: psychometric properties of a brief six item scale for the assessment of depression. Scand J Public Health 2014;42:82-8.

24. Mårdberg B, LUNDBERG ULF, Frankenhaeuser M. The total workload of parents employed in white-collar jobs: Construction of a questionnaire and a scoring system. Scand J Psychol 1991;32:233-9.

25. Virtanen M, Jokela M, Madsen IE, et al. Long working hours and depressive symptoms: systematic review and meta-analysis of published studies and unpublished individual participant data. Scand $J$ Work Environ Health 2018;44:239-50.

26. Nagin DS. Group-Based Modeling of Development. Cambridge, Mass: Harvard University Press, 2005.

27. Nagin DS. Analyzing developmental trajectories: A semiparametric, group-based approach. Psychol Methods 1999;4:139-57.

28. Nagin DS, Odgers CL. Group-based trajectory modeling in clinical research. Annu Rev Clin Psychol 2010;6:109-38.

29. Jones BL, NAGIN DS, ROEDER K. A SAS Procedure Based on Mixture Models for Estimating Developmental Trajectories. Sociol Methods Res 2001;29:374-93.

30. Andruff H, Carraro N, Thompson A, et al. Latent Class Growth Modelling: A Tutorial - Quantitative Methods for. mafiadoc.com https://mafiadoc.com/latent-class-growth-modelling-a-tutorialquantitative-methods-for- 59e6f0c11723ddf42b020f69.html (accessed 24 Nov 2017).

31. indelning S. Socioekonomisk Indelning (SEI): Stat. Cent. http:// www.scb.se/dokumentation/klassifikationer-och-standarder/ socioekonomisk-indelning-sei/. (accessed 23 Nov 2017).

32. Theorell T, Perski A, Akerstedt T, et al. Changes in job strain in relation to changes in physiological state. A longitudinal study. Scand $J$ Work Environ Health 1988;14:189-96.

33. Sanne B, Torp S, Mykletun A, et al. The Swedish Demand-ControlSupport Questionnaire (DCSQ): factor structure, item analyses, and internal consistency in a large population. Scand J Public Health 2005;33:166-74.

34. Chungkham HS, Ingre M, Karasek R, et al. Factor structure and longitudinal measurement invariance of the demand control support model: an evidence from the Swedish Longitudinal Occupational Survey of Health (SLOSH). PLoS One 2013;8:e70541.

35. Jones BL, Nagin DS. Advances in Group-Based Trajectory Modeling and an SAS Procedure for Estimating Them. Sociol Methods Res 2007;35:542-71.

36. Virtanen M, Ferrie JE, Singh-Manoux A, et al. Long working hours and symptoms of anxiety and depression: a 5-year follow-up of the Whitehall II study. Psychol Med 2011;41:2485-94.

37. Cho S-S, Ki M, Kim K-H, et al. Working hours and self-rated health over 7 years: gender differences in a Korean longitudinal study. BMC Public Health 2015;15.

38. Kim I, Kim H, Lim S, et al. Working hours and depressive symptomatology among full-time employees: Results from the fourth Korean National Health and Nutrition Examination Survey (20072009). Scand J Work Environ Health 2013;39:515-20.

39. Wirtz A, Nachreiner F, Rolfes K. Working on Sundays-effects on safety, health, and work-life balance. Chronobiol Int 2011;28:361-70.

40. Alfredsson L, Spetz CL, Theorell T. Type of occupation and nearfuture hospitalization for myocardial infarction and some other diagnoses. Int J Epidemiol 1985;14:378-88.

41. Starrin B, Larsson G, Brenner SO, et al. Structural changes, ill health, and mortality in Sweden, 1963-1983: a macroaggregated study. Int $J$ Health Serv 1990;20:27-42.

42. Väänänen $A$, Kevin MV, Ala-Mursula L, et al. The double burden of and negative spillover between paid and domestic work: associations with health among men and women. Women Health 2004;40:1-18.

43. Glass J, Fujimoto T, Housework FT. Housework, paid work, and depression among husbands and wives. $J$ Health Soc Behav 1994:35:179-91.

44. Hunt K, Annandale E. Just the job? Is the relationship between health and domestic and paid work gender-specific? Sociology of Health and IIIness 1993;15:632-64.

45. Artazcoz L, Cortès I, Escribà-Agüir V, et al. Long working hours and health status among employees in Europe: between-country differences. Scand J Work Environ Health 2013;39:369-78.

46. Nagin D, Tremblay RE. Trajectories of boys' physical aggression, opposition, and hyperactivity on the path to physically violent and nonviolent juvenile delinquency. Child Dev 1999;70:1181-96. 